\title{
Long-term Results Following Surgical Closure of \\ Secundum Atrial Septal Defect
}

Akira Mizuno, Katsuo Fuse, ${ }^{* *}$ Naoki Furuta *

$\mathbf{L}^{\mathrm{o}}$

ONG-TERM results following surgical closure of secundum atrial septal defect were studied, with special reference to arrhythmias and echocardiographic findings in the late postoperative period.

\section{1) Long-term follow-up study}

From January 1954 to March 1974, 513 cases (232 males and 281 females) with secundum atrial septal defect were operated on at the Department of Thoracic Surgery, University of Tokyo. Ages at surgery ranged between 2 to 49 years (Fig. 1). Minor cardiac anomalies were combined in 83 cases (16.2\%). They included pulmonary stenosis with left to right shunt, partial anomalous pulmonary venous connection, persistent left superior vena cava, in order of frequency (Table I). 7 cases $(1.4 \%$ ) were combined with pulmonary hypertension (systolic pulmonary arterial pressure exceeding $70 \mathrm{mmHg}$ ). Defects were closed by modified Gross's procedure $^{1}$ in 3 cases, under hypothermic inflow occlusion combined with selective brain cooling ${ }^{2}$ in 104 cases, and under total perfusion using pumpoxygenator in 406 cases. Almost all correctable minor cardiac anomalies were repaired

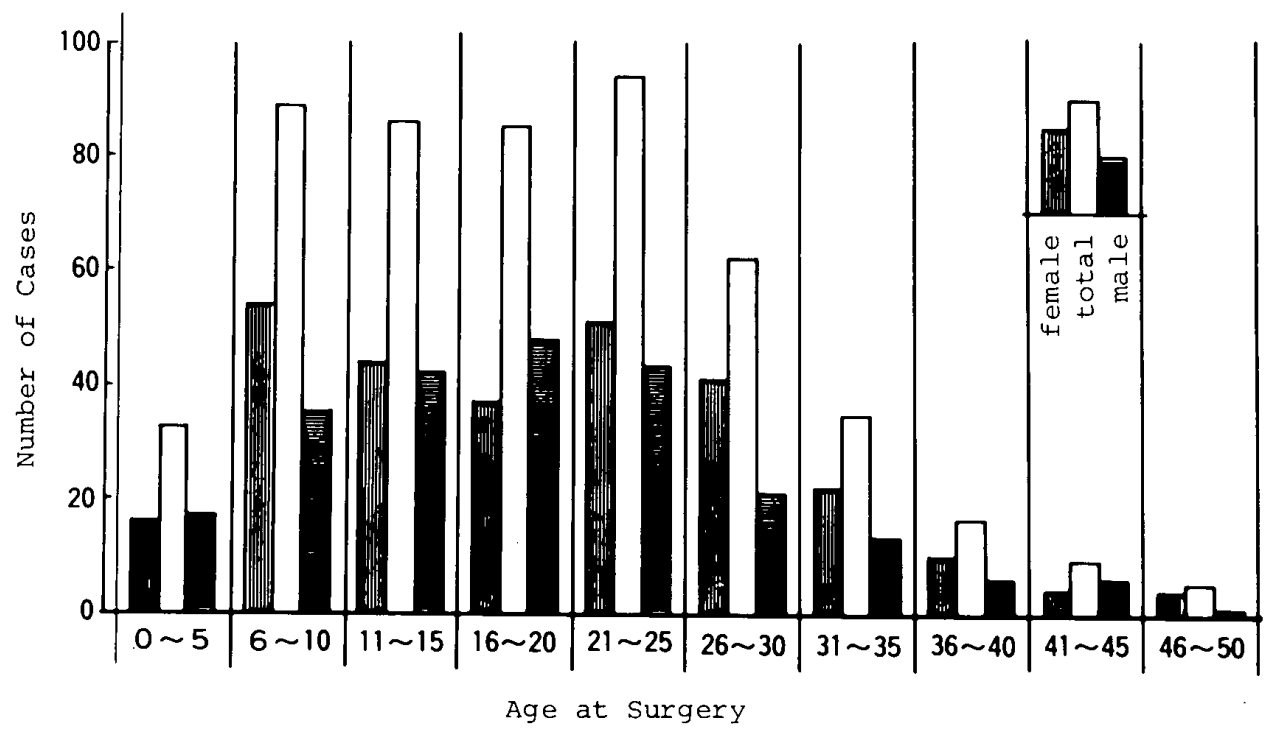

Fig.1. Ages at surgery (all cases).

Key Words:

Long-term follow-up study

Pulmonary arterial hypertension

Postoperative bradyarrhythmias

Postoperative electrophysiologic study

Echocardiography

* Department of Thoracic Surgery, University of Tokyo

** Department of Thoracic Surgery, Juntendo University 
TABLE I COMBINED MINOR CARDIAC ANOMALIES

\begin{tabular}{lc}
\hline Pulmonary stenosis with left to right shunt & 30 cases $(5.8 \%)$ \\
Partial anomalous pulmonary venous connection & 20 cases (3.9\%) \\
Persistent left superior vena cava & 9 cases $(1.8 \%)$ \\
Mitral insufficiency & 6 cases $(1.2 \%)$ \\
Mitral stenosis (Lutembacher syndrome) & 6 cases (1.2\%) \\
Tricuspid insufficiency & 4 cases (0.8\%) \\
Absence of inferior vena cava & 2 cases (0.4\%) \\
Miscellaneous & 6 cases \\
\hline & 83 cases \\
\hline
\end{tabular}

TABLE II LATE DEATH

\begin{tabular}{|c|c|c|c|c|}
\hline \multicolumn{3}{|c|}{ Age and sex } & Interval between surgery and late death & \multirow{2}{*}{$\frac{\text { Cause of late death }}{\text { uncorrected mitral stenosis }}$} \\
\hline 1. & $23 y r s$ & female & $14 y r s$ and 6 mon. & \\
\hline 2. & $17 y r s$ & male & $3 y r s$ and 4 mon. & unknown \\
\hline 3. & $17 y r s$ & male & $2 y r s$ and 1 mon. & recurrent tricuspid insufficiency \\
\hline 4. & 29 yrs & female & $6 y r s$ and 2 mon. & unknown \\
\hline 5. & $24 y r s$ & female & 10 yrs and 3 mon. & sick sinus syndrome \\
\hline 6. & $22 y r s$ & male & 9 yrs and 10 mon. & unknown \\
\hline 7. & $23 y r s$ & female & 10 yrs and 6 mon. & $\begin{array}{l}\text { accident, P.M.* had been } \\
\text { implanted } 9 \text { yrs after surgery }\end{array}$ \\
\hline 8. & $8 y r s$ & female & $6 y$ rs and 2 mon. & another surgery \\
\hline 9. & 17 yrs & male & $2 y r s$ and 1 mon. & automobile accident \\
\hline 10. & $16 y r s$ & male & $2 y r s$ and 5 mon. & respiratory infection \\
\hline
\end{tabular}

* artificial pacemaker

concomitantly with the closure of the defect. Defects were repaired either using a pericardial or prosthetic patch in 32 cases, or by suture closure in the remainders. Operative deaths were encountered in 19 cases $(3.7 \%)$.

5 to 24 years follow-up studies were performed for survivors by direct contacts or questionaires. Mean follow-up period was 12.4 years. 13 cases (2.6\%) out of 494 survivors were lost to followup. Late deaths were encountered in 10 cases $(2.1 \%)$. Intervals between surgery and late death were distributed between 2 to 14 years. In 3 cases, causes of late death remained unknown (table II). 4 cases with residual shunts due to reopening or inadequate closure of the defect were successfully re-operated on 8 to 19 years after the initial surgery. In these cases defects were
TABLE III LONG-TERM RESULTS FOR 494 SUR VIVORS

\begin{tabular}{cr}
\hline \hline Alive & 467 cases (94.5\%) \\
N.Y.H.A.I & 434 cases (87.9\%) \\
N.Y.H.A. II & 13 cases ( 2.6\%) \\
not classified & 20 cases ( 4.0\%) \\
Re-operation & 4 cases ( 0.8\%) \\
Late death & 10 cases ( 2.1\%) \\
Lost to follow-up & 13 cases ( 2.6\%) \\
\hline
\end{tabular}

repaired using a prosthetic patch. Functional classifications were determined for survivors. 434 cases $(87.9 \%)$ were classified as N.Y.H.A. I, and 13 cases were as N.Y.H.A. II. 20 cases 
TABLE IV CAUSES OF LIMITED ACTIVITIES IN CASES CLASSIFIED AS N.Y.H.A. II

Supraventricular bradycardia

Sinus bradycardia

2nd degree heart block

Pace maker implantation

Obstructive pulmonary vascular disease

Paroxysmal atrial flutter

Other diseases except for cardiovascular disease
3 cases

1 case

2 cases

1 case

3 cases

1 case

2 cases

TABLE V INCIDENCE OF LATE ARRHYTHMIAS IN RELATION TO AGE AT SURGERY

\begin{tabular}{cccc}
\hline \hline Age at surgery & Number of cases & Number of cases with late arrhythmias \\
under 10 yrs & 66 & $11(16.7 \%)$ & $p_{0.02 *}^{*}$ \\
$11-30 y r s$ & 171 & $10(5.8 \%)$ & N.S.* \\
over 31 yrs & 49 & $7(14.3 \%)$ & \\
\hline
\end{tabular}

${ }^{*}$ Chi square analysis with Yates correction

TABLE VI HIS BUNDLE ELECTROGRAM AND OVERDRIVE SUPPRESSION TEST

\begin{tabular}{|c|c|c|c|c|c|c|c|}
\hline & & Rhythm at study & $\begin{array}{c}A-H \\
\text { intervals } \\
\text { (msec) }\end{array}$ & $\begin{array}{c}H-V \\
\text { intervals } \\
\text { (msec) }\end{array}$ & $\begin{array}{c}S R T \\
(m s e c)\end{array}$ & $\begin{array}{l}\text { CSRT } \\
\text { (msec) }\end{array}$ & $\begin{array}{c}\text { Atrial pacing rate } \\
\text { at appearance of } \\
\text { 2nd degree heart block }\end{array}$ \\
\hline 1. & 17 yrs female & Sinus bradycardia & 80 & 45 & $\begin{array}{c}5240 \\
\left(2480^{*}\right)\end{array}$ & 4080 & over 150 pulse/min \\
\hline 2. & 8 yrs female & Sinus rhythm & 80 & 40 & 1260 & 420 & 100 \\
\hline 3. & 23 yrs female & Junctional rhythm & & 40 & $3600^{*}$ & & over 150 pulse/min \\
\hline 4. & 36 yrs male & Sinus bradycardia & 120 & 35 & $5000^{* *}$ & $3960 * *$ & \\
\hline 5. & 6 yrs female & Sinus rhythm & 110 & 35 & 1440 & 560 & 130 \\
\hline 6. & 17 yrs male & Sinus rhythm & 100 & 35 & 1840 & 880 & over 150 pulse $/ \mathrm{min}$ \\
\hline 7. & 5 yrs male & 2nd degree heart block & indefinite & 40 & & & \\
\hline
\end{tabular}

*automaticity recovery time

**no ventricular contraction occurred 5 seconds after cessation of atrial pacing

(4.0\%) were not classified due to indirect informations (Table III). 3 cases out of 13 cases who were classified as N.Y.H.A. II were thought to have obstructive changes in the pulmonary arterial vasculatures. All 3 cases were with pulmonary hypertension preoperatively. Limited activities in 6 cases as classified into N. Y. H. A. II were caused by postoperative bradyarrhythmias (Table IV). One of them was implanted an artificial pacemaker 13 years after surgery. In one case out of 10 cases of late death an artificial pacemaker had been implanted 9 years after surgery, due to heart failure caused by brady- cardia. Another one died from bradycardiatachycardia syndrome (sick sunus syndrome) in another hospital (Table II).

These results suggested that significant late postoperative dysrhythmias and preoperative severe pulmonary vascular change adversely affect the long-term results of surgical closure of secundum atrial septal defect.

2) Arrhythmias in the late postoperative period

Among 513 cases, 301 cases were operated on after January 1965 , by usual surgical procedure using pump-oxygenator. Pre- and post-operative 


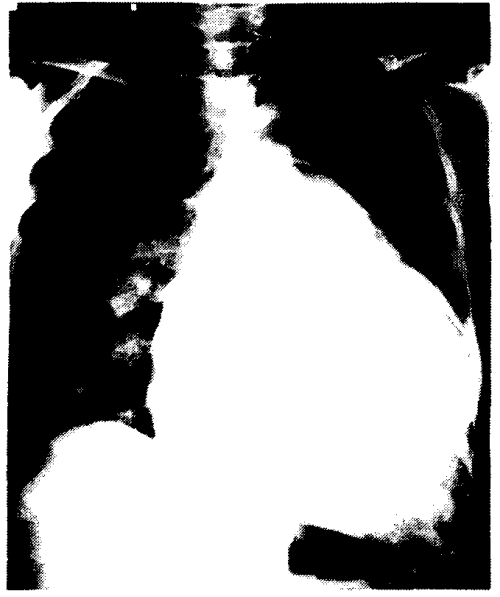

BEFORE SURGERY

P.A.PR. : $90 / 40$ MMHG

T.P.V.R. : 377 DYNES.SEC.CM ${ }^{-5}$
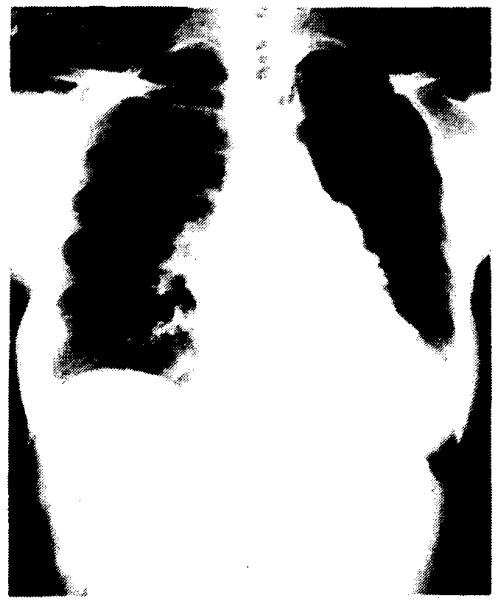

12 Years after SuRgery

P.A.PR, : 26/15 MMHG

T.P.V.R. : 169 DYNES.SEC.CM ${ }^{-5}$

Fig.2. Case with pulmonary arterial hypertension.

P.A.Pr.: pulmonary arterial pressure

T.P.V.R.: total pulmonary vascular resistance

$$
\text { ASD } \bar{C} \text { PH Y.N., } 27 \text { YRS OLD, FEMALE }
$$
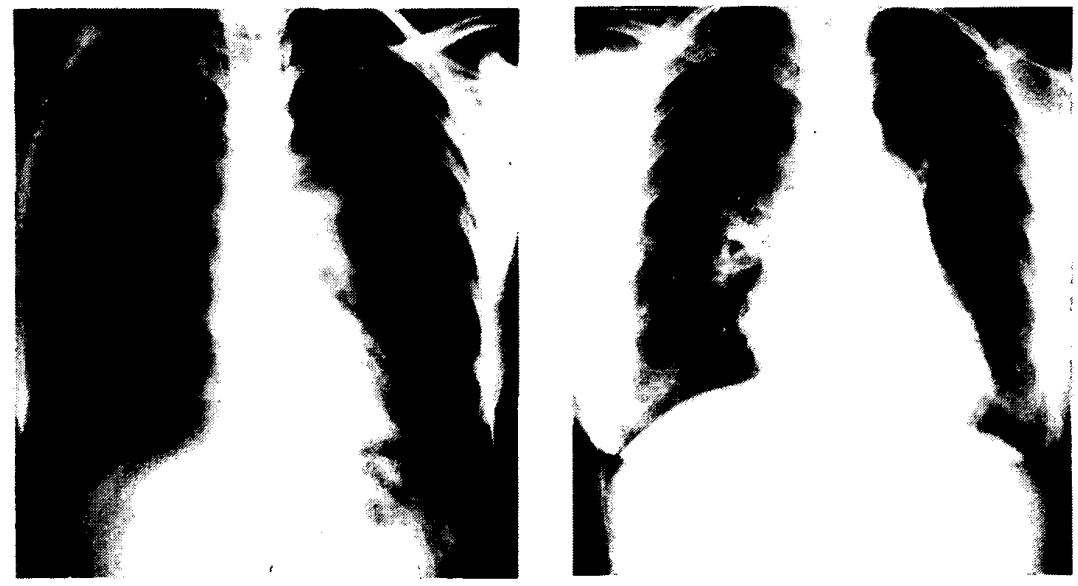

BEFORE SURGERY

17 YEARS AFTER SURGERY

P.A.PR, : 75/30 MMHG

T.P.V.R. : 285 DYNES.SEC. $\mathrm{CM}^{-5}$

$P, A, P R,: 52 / 26$ MMHG

T.P.V.R. : $3 I 2$ DYNES $\cdot S E C \cdot \mathrm{CM}^{-5}$

Fig.3. Case with pulmonary arterial hypertension. Abbreviations: as same as Fig. 2.

electrocardiographic recordings were obtained on 286 cases, excluding cases with operative death ( 9 cases, $3.1 \%$ ) and with pre-operative arrhyth- mias (6 cases, $2.1 \%$ ). 33 cases $(11.5 \%$ of 286 cases) were combined with minor cardiac anomalies, and 4 cases $(1.4 \%)$ were with pulmonary 
TABLE VII ARTERIAL OXYGEN SATURATION

\begin{tabular}{lccc}
\hline \hline & Number of cases & Arterial oxygen saturation (\%) & \\
\hline with pulmonary hypertension * & 7 & $92.0 \pm 1.4$ & $<0.02$ \\
without pulmonary hypertension & 20 & $94.6 \pm 2.2$ & $p$ \\
\hline
\end{tabular}

*systolic pulmonary arterial pressure exceeding $70 \mathrm{mmHg}$

TABLE VIII LVDs, LVDd, AND EJECTION FRACTION

\begin{tabular}{cccc}
\hline \hline Age at study & LVDs & LVDd & Ejection fraction* \\
\hline under 20 yrs $n=14$ & $23.6 \pm 6.2$ & $39.7 \pm 4.7$ & 0.79 \\
$21-30$ yrs $n=24$ & $28.9 \pm 7.0$ & $43.8 \pm 6.7$ & 0.71 \\
$31-40$ yrs $n=22$ & $29.4 \pm 6.7$ & $45.6 \pm 7.1$ & 0.73 \\
over 41 yrs $n=11$ & $29.5 \pm 5.5$ & $44.8 \pm 7.1$ & 0.72 \\
\hline
\end{tabular}

LVDs: systolic left ventricular diameter

LVDd: diastolic left ventricular diameter

*calculated from mean values

hypertension preoperatively. Arrhythmias in the early postoperative period (within one year after surgery) were observed in 85 cases (29.7\%). Predominant arrhythmias were junctional rhythm in $22 \%$, ectopic atrial rhythm in $14 \%$, 2nd degree heart block in $7 \%$, and so on. Incidences of early arrhythmias were significantly higher in older cases (over 31-year old, $p<0.02$ ), in cases with minor cardiac anomalies $(\mathrm{p}<0.01)$, sinus venosus type defect $(\mathrm{p}<0.02)$, and patch closure of the defect $(\mathrm{p}<0.001)$. Excluding 3 cases lost to follow-up and one case of late death 2 years after surgery, 282 cases were followed up electrocardiographically 5 to 14 years after surgery. 35 cases ( $12.4 \%$ of 282 cases) exhibited several kinds of arrhythmias in the late postoperative

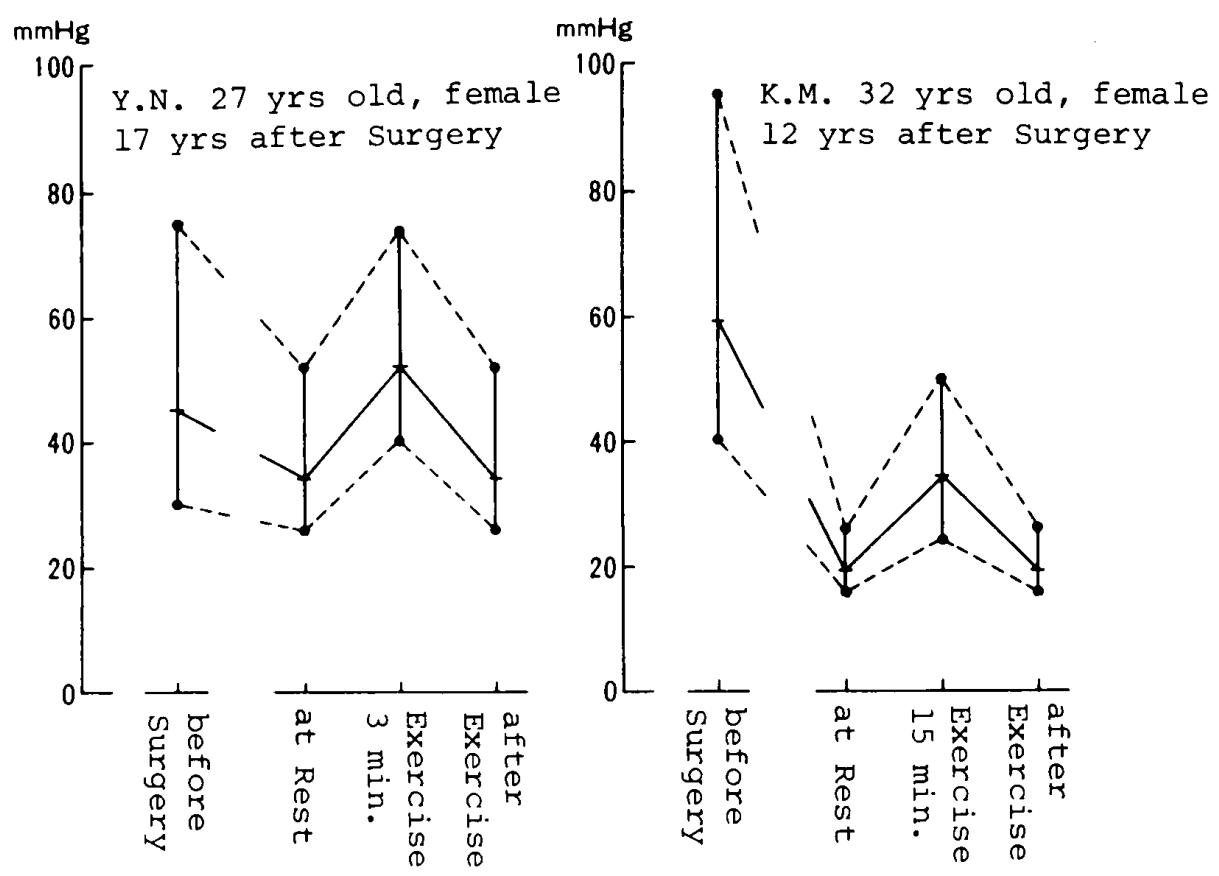

Fig.4. Exercise response of the pulmonary arterial pressure in the late postoperative period.

(left; case in Fig.3, right; case in Fig. 2) 
TABLE IX VENTRICULAR SEPTAL MOTION : NUMBER OF CASES SHOWING LEFT VENTRICULAR DOMINANT PATTERN

\begin{tabular}{|c|c|c|c|c|}
\hline \multirow{2}{*}{$\begin{array}{l}\text { Age at surgery } \\
\text { under } 10 \text { yrs }\end{array}$} & \multicolumn{3}{|c|}{$L V$ dominant pattern / total case } & \multirow{2}{*}{$\begin{array}{l}\% \\
50\end{array}$} \\
\hline & 9 & 1 & 18 & \\
\hline $11-20 y r s$ & 9 & I & 21 & 43 \\
\hline $21-30 y r s$ & 17 & l & 26 & 65 \\
\hline over 31 yrs & 7 & 1 & 12 & 58 \\
\hline
\end{tabular}

TABLE X RVD/LVD

\begin{tabular}{|c|c|c|c|}
\hline \multirow{2}{*}{ Age at surgery } & \multirow{2}{*}{11 cases } & \multicolumn{2}{|c|}{ Intervals between surgery and study } \\
\hline & & 5 to 10 yrs (mean: $7.7 \mathrm{yrs}$ ). & 10 to $26 \mathrm{yrs}$ (mean: $14.6 \mathrm{yrs}$ ) \\
\hline under 10 yrs & $\begin{array}{l}0.43 \pm 0.10 \\
(n=16)(1)\end{array}$ & $0.50 \pm 0.10$ & $0.39 \pm 0.08$ \\
\hline $11-30 y r s$ & $\begin{array}{l}0.50 \pm 0.15 \\
(n=45)\end{array}$ & $0.48 \pm 0.15$ & $0.51 \pm 0.08$ \\
\hline over 31 yrs & $\begin{array}{l}0.57 \pm 0.15 \\
(n=11)(2)\end{array}$ & $0.58 \pm 0.19$ & $0.57 \pm 0.14$ \\
\hline
\end{tabular}

$$
\begin{gathered}
\text { (1)-(2): } p<0.01 \quad \text { (3) }-(4): p<0.01 \quad(3)-(5): p<0.05 \quad(4)-(6): p<0.05 \\
\text { RVD: right ventricular diameter } \\
\text { LVD: left ventricular diameter }
\end{gathered}
$$

period. All but two cases were included in cases with early postoperative arrhythmias. 7 cases out of 35 cases reverted to sinus rhythm 2 to 14 years after surgery. Incidences of late postoperative arrhythmias were significantly higher in cases who were operated on at age less than 10 years (Table V). Consistent bradycardias were encountered in 17 cases out of 28 cases with late postoperative arrhythmias. These bradycardias showed progressive nature, and artificial pacemakers were implanted in two cases, as mentioned above. In 7 cases out of 17 cases with bradycardia, His bundle electrogram recordings and overdrive suppression tests by rapid atrial pacing were performed 2 to 9 years after surgery. $\mathrm{H}-\mathrm{V}$ intervals were distributed within normal range in all cases, and 2nd degree heart block in case 7 was prove to be A-H block (Table VI). In 4 cases, overdrive suppression tests exhibited marked prolongation of sinus node recovery time (SRT), or automaticity recovery time. Developments of 2nd degree heart block were observed in other two cases with normal or slightly prolonged corrected SRT, during atrial pacing with the frequency less than 130 per minute (Table VI).

These findings suggested that, suppression of sinus node function, and/or some functional disturbances in atrioventricular conduction might present in those cases with late postoperative bradyarrhythmias.

\section{3) Pulmonary arterial hypertension}

In 7 cases (1.4\% of 513 cases), systolic pulmonary arterial pressure exceeded $70 \mathrm{mmHg}$ preoperatively. There was one operative death, whose pulmonary arterial system was proved to have extreme sclerotic obstructive changes by autopsy. The ages at surgery of these cases were distributed between 27 and 45 years, and 3 cases were above 40 years of age. Slight arterial desaturations were present in all cases, and arterial oxygen saturations were significantly lower than those without pulmonary arterial hypertension (Table VII). Functional status of 6 cases excluding one operative death in the longterm period was classified as N.Y.H.A.I in 3 cases, and N.Y.H.A. II in other 3 cases. In two cases, right heart catheterizations were performed 12 and 17 years after surgery. One case with N.Y.H.A. I functional classification had reduced heart size and normal pulmonary arterial pressures at rest (Fig. 2). Another case with N.Y.H.A. II functional classification had cardiomegaly and pulmonary arterial hypertension at rest (Fig. 3). 
During exercise, although the former tolerated the exercise with minimal increase in the pulmonary arterial pressures, the later could not tolerate the exercise showing marked elevation in the pulmonary arterial pressures (Fig. 4).

Preoperative marked pulmonary arterial hypertension might affect adversely late postoperative functional status in some cases.

\section{4) Echocardiographic findings in the late post- operative period}

In 77 cases excluding cases with pulmonary arterial hypertension, M-mode echocardiograms were recorded 5 to 24 years after surgery. Systolic and diastolic left ventricular diameters were tabulated according to ages at the recording (Table VIII). They distributed in normal range in every age groups, and calculated ejection fractions from their mean values also ranged within normal values, suggesting that no abnormal changes had not occurred in the left ventricular functions. Normal patterns (left ventricular dominant type) in the ventricular septal motion were observed in only half of all cases (Table IX). Diameter ratios of the right ventricle to the left ventricle were calculated. 16 cases who were operated at the age less than 10 years had significantly lower values than 11 cases who were operated on at the age more than 31 years. It has been said that the right ventricular diameters did not diminish in the long-term period after surgical closure of secundum atrial septal defect? In the group who were operated on at the age less than 10 years, cases who were studied over 11 years after surgery had significantly lower values as compared with cases studied less than 10 years after surgery (Table $\mathrm{X}$ ).

Accordingly, it was possible to expect the reduction of the right ventricular diameter after surgical closure of secundum atrial septal defect in the younger cases. Although reduction in the right ventricular diameter was unusual in many cases, good functional status was achieved in the long-term period.

\section{CONCLUSIONS}

Long-term results after surgical closure of secundum atrial septal defect were excellent in the majority of cases. Main factors adversely affecting long-term results were preoperative obstructive pulmonary arterial vascular changes and late postoperative bradycardias. Echocardiographic findings suggested good left ventricular function in the late postoperative period. Enlarged right ventricular diameters and abnormal ventricular septal motions, revealed mainly in the aged group, did not affect long-term functional status.

It was considered to be important that further extensive researches were neccesary to clarify the etiology of conduction disturbances after surgical closure of secundum atrial septal defect.

\section{REFERENCES}

1. GROSS RE, WATKINS Jr E: Surgical closure of atrial septal defects. Arch Surg 67: 670, 1953

2. KIMOTO S, SUGIE S, ASANO K: Open heart surgery under direct vision with the aid of brain cooling by irrigation: Experimental studies and results of clinical cases, including three successfully treated cases of atrial septal defect. Surg 39: 592, 1956

3. PEARLMAN AS, BORER JS, CLARK CE et al: Abnormal right ventricular size and ventricular septal motion after atrial septal defect closure. Am J Cardiol 41: 295, 1978 